\title{
Integralidad en el Análisis de Trayectorias Educativas
}

\author{
Verónica Filardo \\ 'Facultad de Ciencias Sociales, Universidad de la República - Uruguay
}

RESUMEN - Integralidad en el Análisis de Trayectorias Educativas. Dos ideas-fuerza estructuran el artículo. La primera es: para analizar las trayectorias educativas, éstas deben integrar los diferentes niveles educativos. Ello requiere información individualizada y acumulativa de los resultados en los distintos ciclos. De esta forma es posible observar la determinación que los resultados en un nivel ejerce sobre los siguientes. La segunda idea-fuerza es que el sistema educativo es uno de los tantos ámbitos en que los jóvenes transitan. Las trayectorias educativas se ven impactadas por lo que sucede en otros espacios de la vida de los individuos (trabajo, familia, hijos) y recíprocamente. Una mirada integral tiene implicaciones para el diseño de políticas educativas, programas públicos de primer empleo, programas de promoción de la autonomía, políticas de fecundidad, etc. Se muestra evidencia empírica para el caso de Uruguay.

Palabras-clave: Trayectorias Educativas. Uruguay. Políticas Educativas.

ABSTRACT - Comprehensiveness in the Analysis of Educational Paths. Two key points structure the paper. The first one is that, in order to analyze the educational paths, they must be part of the distinct educational levels. It is necessary to have individualized and cumulative information of the outcomes in the different cycles. This way, it is possible to observe the determination exerted by the outcomes from one level on the following ones. The second key point is that the educational system is one among several scopes where the youth circulate. The educational paths suffer impact from what happens in other scopes of the individuals' lives (work, family, children etc.) and vice versa. A comprehensive look has implications for the design of educational policies, first job public programs, programs for autonomy fostering, policies of fertility etc. Empirical evidence from the Uruguayan case is shown.

Keywords: Educational Paths. Uruguay. Educational Policies.

Educação \& Realidade, Porto Alegre, v. 41, n. 1, p. 15-40, ene./mar. 2016. 15 http://dx.doi.org/10.1590/2175-623660934 
Integralidad en el Análisis de Trayectorias Educativas

El artículo tiene dos ideas-fuerza: en primer lugar que para analizar las trayectorias educativas, éstas deben integrar los diferentes niveles educativos. Ello requiere información individualizada y acumulativa de los resultados educativos en los distintos ciclos. De esta forma es posible identificar los problemas en términos agregados por niveles y además observar la determinación que los resultados de un nivel ejerce sobre los siguientes. Para ello se construye una tipología de trayectorias educativas y se cuantifica la proporción de estudiantes que recorren cada una en Uruguay, en 2008. Asimismo se identifica que la repetición en el primer nivel (aprobación de Primaria con rezago o extraedad) determina la probabilidad de egreso de Educación Media.

La segunda idea-fuerza es que el sistema educativo es uno de los tantos ámbitos en que los jóvenes transitan. Por tanto las trayectorias educativas se ven impactadas, influenciadas o comprometidas por lo que sucede en otros espacios de la vida de los individuos (como el trabajo, la familia, los hijos) y recíprocamente. Las relaciones con estos otros ámbitos reconocen además especificidades según género. Una mirada integral requiere el análisis de otros recorridos biográficos, además del educativo, y tiene implicaciones relevantes en el diseño de políticas educativas, pero también de programas públicos de primer empleo en jóvenes, programas de promoción de la autonomía, políticas de fecundidad, etc. La influencia recíproca de estos eventos (la salida del sistema educativo, el ingreso al mercado de empleo, la salida del hogar de origen o el nacimiento de hijos) presenta aspectos particulares según sector social. Esto se evidencia tanto en las edades a las que ocurren los eventos (calendarios) como por el orden en que se dan (secuencia) y la proporción de jóvenes que los experimentan (intensidad). Si bien existen diferencias entre los jóvenes de un país, también se registran entre países, producto de diferentes regímenes de transición (Casal, 1996). La comparación de las respuestas que los jóvenes dan de los motivos que atribuyen a su desvinculación del sistema educativo sin haber terminado la Educación Media habilitan esta línea de análisis.

\section{Trayectorias Educativas}

En el 2008, se aprueba en Uruguay la Ley General de Educación ( $\mathrm{N}^{\circ}$ 18.437) que establece 14 años de educación formal obligatoria, lo que equivale a la aprobación de la Educación Media Superior ${ }^{1}$. Según datos de la ENAJ $(2008)^{2}$, uno de cada tres jóvenes urbanos de 20 a 29 años, habían aprobado este nivel en el 2008, lo que implica cifras que ubican al país en las posiciones más bajas en el ranking regional, colocando la cuestión educativa como uno de los principales issues de la agenda social y política del país. La universalización del egreso de la Educación Media a la que aspira la Ley, coloca un desafío de gran magnitud y su cumplimiento es firmemente argumentado - pese a los escasísimos avances registrados - desde hace más de dos décadas, por todos los sectores del espectro político nacional ${ }^{3}$.

16 Educação \& Realidade, Porto Alegre, v. 41, n. 1, p. 15-40, ene./mar. 2016. 
El nivel primario (teóricamente 6 años de educación formal) registra en el 2008 para el tramo de entre 20 a 29 años un egreso universal (representa el 97\% de los jóvenes del tramo con ese nivel aprobado). Uruguay alcanza altos niveles de cobertura y egreso en el nivel primerio muy tempranamente en el concierto regional. Sin embargo, la repetición en Primaria es una constante histórica y se revela con alto poder de determinación de trayectorias educativas en el siguiente nivel.

Para mostrarlo se construye un tipología de trayectorias educativas desde que los individuos ingresan en el sistema educativo formal hasta la finalización del nivel medio (Primaria y Educación Media) ${ }^{4 ; 5}$. Se considera el tramo de jóvenes de 20 a 29 años, dado que la edad idealmente establecida de egreso de Educación Media se sitúa en los 18 años. De esta forma todos los individuos pertenecen a la población en riesgo (tienen edad como para haber culminado el nivel medio).

Para construir la tipología se considera:

1. Si se egresa de primaria o no ${ }^{6}$.

2. Si se egresa de Primaria se discrimina quienes a. egresan del nivel con extraedad (los que repiten al menos un año en Primaria son el $23 \%$ de los que egresan del nivel) y b. transitan de primer a sexto grado con aprobaciones sucesivas (egreso a la edad teórica para ello) que alcanzan a ser el 77\% de los que aprueban Primaria.

3. En cualquiera de las dos situaciones (egreso de primaria con extraedad, o en la edad teórica) el recorrido puede ser: o bien se ingresa a educación media, o bien se trunca la trayectoria educativa habiendo aprobado este nivel.

4. Al momento del relevamiento, los jóvenes que iniciaron Educación Media ${ }^{7}$ se encuentran en alguna de las siguientes situaciones: a) aprobaron el nivel medio; b) desertaron del sistema educativo; c) continúan asistiendo a centros educativos de nivel medio.

5. Por último, puede distinguirse entre los que lograron completar la Educación Media aquellos que egresan con rezago (repitieron algún año en este nivel) o bien el egreso se produce en los plazos previstos para ello.

Como se aprecia en el diagrama siguiente el 33\% de los jóvenes de 20 a 29 años aprobaron el nivel medio en 2008, lo que supone una tasa de egreso muy baja al compararse con los países de la región. Por otro lado, considerando solo los que egresan del nivel medio el $97 \%$ no presentan rezago en Primaria. Dicho de otro modo; de los que repitieron algún año en Primaria solo el 4,5\% logra culminar la Educación Media; en cambio del conjunto de jóvenes que no repitieron en Primaria el 42,4\% logran aprobar el nivel medio. Se refleja así la determinación que ejerce el egreso con extraedad del nivel primario en la probabilidad de egresar de Educación Media.

Educação \& Realidade, Porto Alegre, v. 41, n. 1, p. 15-40, ene./mar. 2016. 


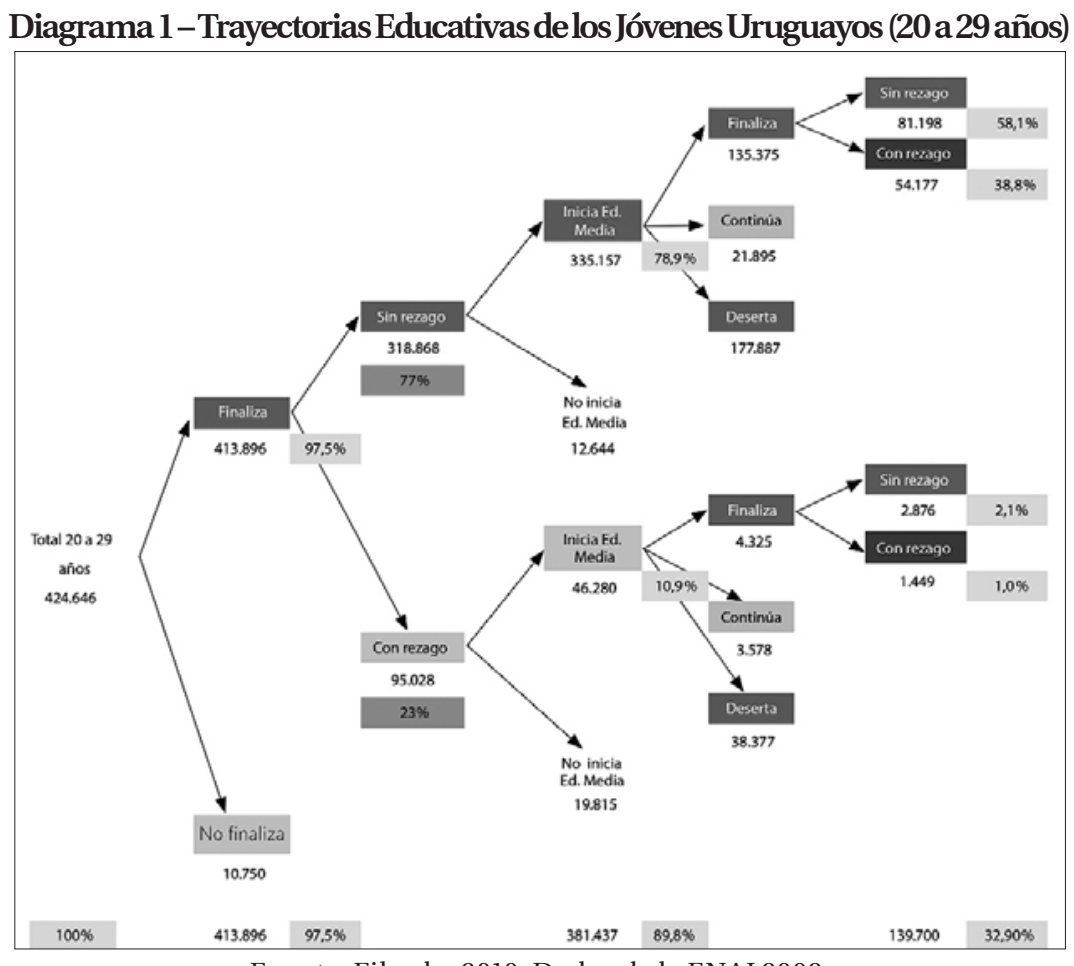

Fuente: Filardo, 2010. Dados de la ENAJ 2008.

Enfunción del esquema anterior, se establecen cinco tipos de trayectorias educativas.

La Trayectoria Esperadaes recorridapor los jóvenes que cumplen en tiempo y forma lo que establece como obligatorio la Ley General de Educación del 2008: culminan la educación media y lo hacen en el plazo hipotéticamente establecido para ello. Son el 19\% del total de jóvenes del tramo de 20 a 29 años en la ENAJ 2008.

\section{Diagrama 2}

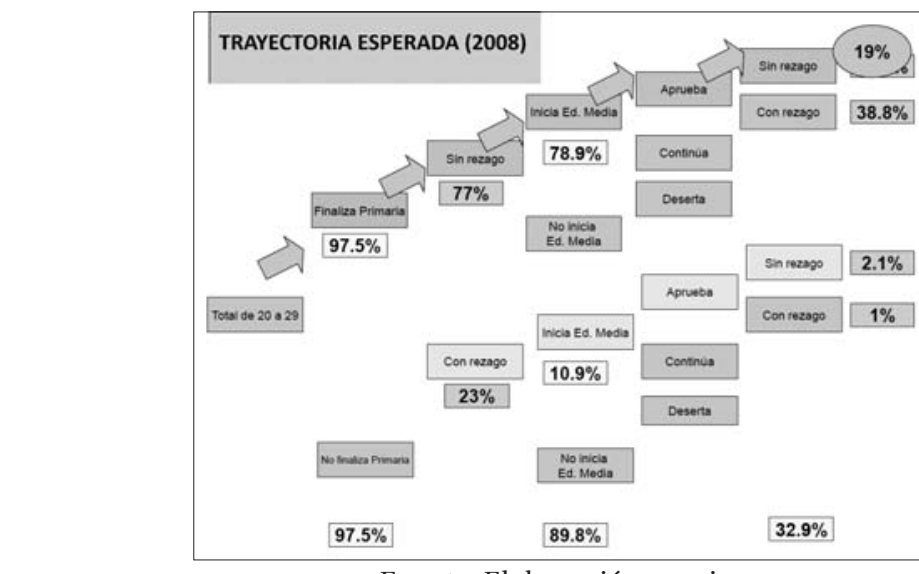

18 Educação \& Realidade, Porto Alegre, v. 41, n. 1, p. 15-40, ene./mar. 2016. 
La Trayectoria Esperada Lenta representa al 13.7\% de los jóvenes de 20 a 29 años, que aprueban el nivel medio pero en más tiempo del previsto. El rezago puede haber sido producido tanto por repetición en Primaria o en el nivel medio. Debe notarse que el $12.7 \%$ son quienes repiten sólo en educación media, lo que significa que el $1 \%$ de los que venían con extraedad de primaria logran culminar la educación media (habiendo repetido en este nivel o no).

Diagrama 3

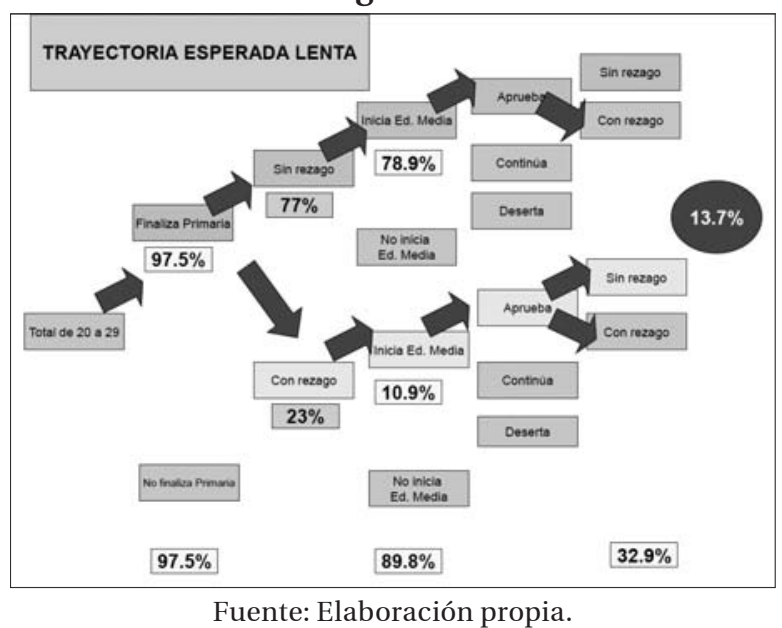

La Trayectoria Trunca Temprana corresponde a aquellos jóvenes que habiendo culminado la educación primaria no inician el nivel medio. Representa casi al 8\% de los jóvenes del tramo de 20 a 29 años.

Diagrama 4

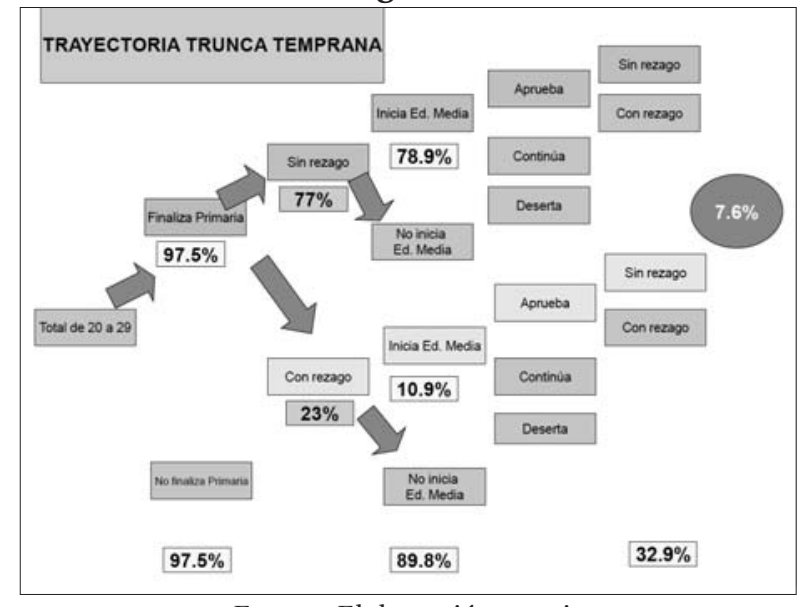

Fuente: Elaboración propia. 
En la Trayectoria Trunca Media se clasifican los y las jóvenes que habiendo iniciado el nivel medio desertan del sistema educativo sin haber aprobado este nivel. Representa a más de la mitad de los jóvenes del tramo de edad (51\%).

\section{Diagrama 5}

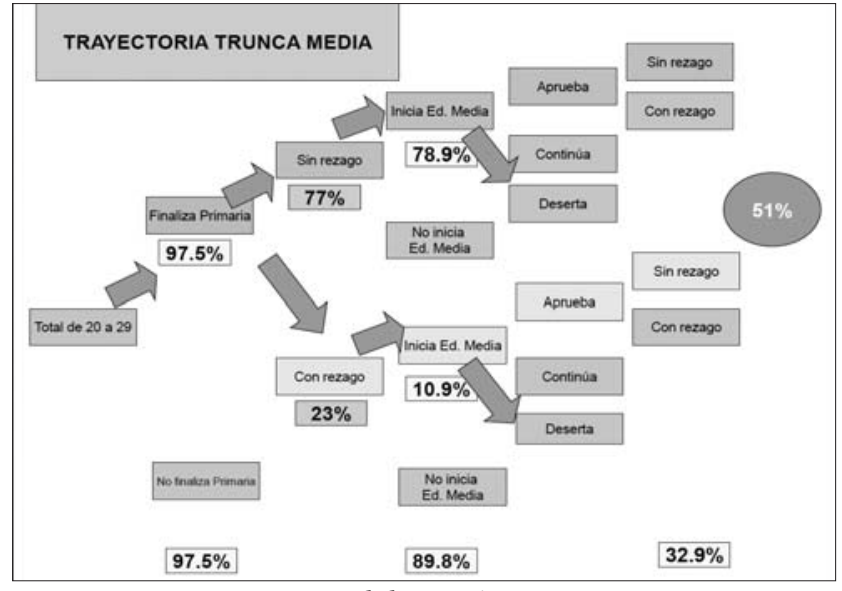

Fuente: Elaboración propia.

Por último, la Trayectoria Inconclusa corresponde a los jóvenes que teniendo entre 20 y 29 años están asistiendo al momento de la encuesta a establecimientos educativos de nivel medio, ya sea por sucesivos años de repetición o por retorno al sistema educativo luego de períodos de desafiliación al mismo. Representan el 6\% del tramo de edad.

\section{Diagrama 6}

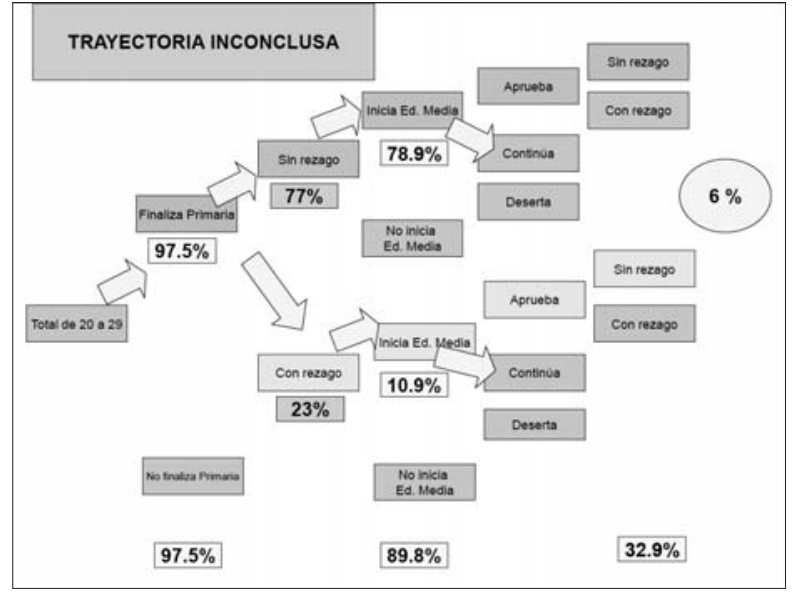

Fuente: Elaboración propia. 
Ahora bien, las trayectorias educativas muestran inequidades, entendiendo por éstas, aquellos factores socio-culturales o económicos de origen de los alumnos que generan de forma sistemática ciertos resultados educativos que el sistema no logra amortiguar.

Pese a que el Uruguay es uno de los países menos inequitativos de la región en la distribución del ingreso, las inequidades que se presentan en los resultados educativos son mayores que las de sus vecinos. En el 2008 de los jóvenes que viven en hogares pobres egresan del nivel medio el $6,4 \%$ frente a un $36,4 \%$ de los que viven en hogares no pobres. Los guarismos de egreso entre jóvenes que están en situación de pobreza o no, superan los que se registran en Chile, Argentina y Brasil, que tienen distribuciones de renta más inequitativas que la de Uruguay (De Armas; Retamoso, 2010). También se registran desigualdades en los niveles de aprendizajes según las pruebas PISA, asociadas a las posiciones que se ocupen en la estructura social, y el tipo de centro de educativo al que se asista (tanto sea liceos o escuelas técnicas, o del sector público y privado). En el 2009, el Uruguay aún ocupaba el primer lugar en la región en las pruebas PISA; en el 2012 no sólo desciende su puntaje promedio en todas las áreas de conocimiento, sino que se ubica por debajo de Chile y México, en el ranking regional; siendo uno de los ocho países de los 65 estudiados que disminuye su promedio entre el 2009 y el 2012 (ANEP, 2013).

Enfatizaremos aquí dos aspectos de las desigualdades de los resultados educativos, considerando las trayectorias construidas: los mejores resultados educativos que obtienen las mujeres frente a los varones del mismo rango de edad y las brechas que se presentan en función de las condiciones de partida de los jóvenes tomando como indicador el clima educativo del hogar de origen ${ }^{8 ; 9}$.

La gráfica 1 muestra diferencias por sexo en el desempeño educativo de varones y mujeres de entre 20 y 29 años: las mujeres obtienen en conjunto una mayor escolarización (culminan educación media el $39 \%$ de las mujeres frente al $28 \%$ de los varones); además lo hacen en mayor proporción en los tiempos esperados (24\% de las mujeres frente al 15\% de los varones). No hay diferencias según sexo en las trayectorias truncas tempranas - las que tienen el fin de su recorrido educativo al finalizar primaria -, ni en la trayectoria inconclusa - a la que pertenecen aquellos que aún están asistiendo a centros educativos de nivel medio. La trayectoria trunca media es predominante para los dos sexos aunque manifiesta un porcentaje mayor de varones (el $47 \%$ de las mujeres y el $57 \%$ de los hombres). 


\section{Gráfica 1 - Trayectorias Educativas por Sexo}

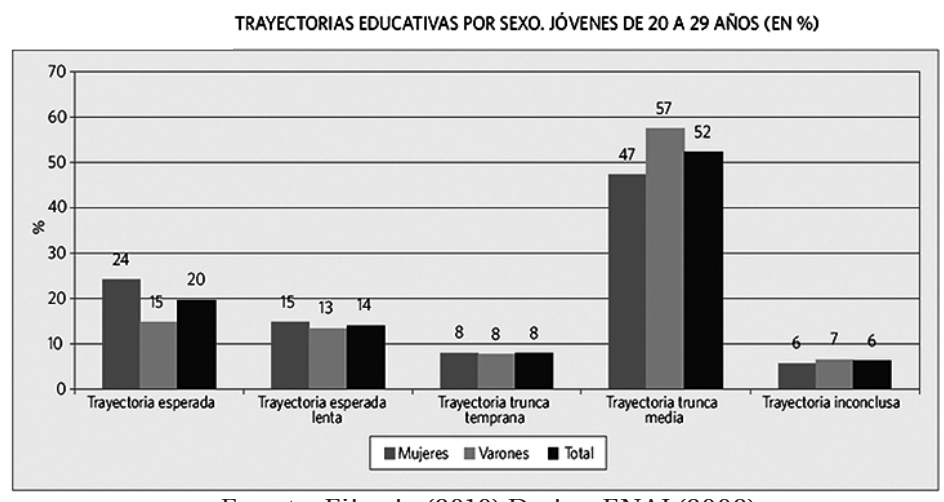

Fuente: Filardo (2010) Dados ENAJ (2008).

Los desempeños educativos de las mujeres son mejores que los de los varones en varios indicadores. Las mujeres tienen más años de escolarización, aprueban educación media en mayor proporción y describen trayectorias esperadas con mayor frecuencia relativa que los varones. Asimismo las tasas de repetición se distribuyen diferencialmente por sexo, desde Primaria. La experiencia de repetición se verifica en mayor proporción entre los varones y crece en las cohortes más jóvenes el porcentaje de varones que repiten más de una vez, lo que muestra que la extraedad al egreso de primaria se incrementará para los varones entre 12 y 14 años en el 2008 (Filardo, 2010) ${ }^{10}$.

El clima educativo del hogar ${ }^{11}$ del que provienen los jóvenes tiene una determinación relevante en las trayectorias educativas que recorren éstos. Dentro de quienes aprueban educación media hasta los 29 años, se encuentran más de la mitad de los jóvenes que provienen de hogares de clima educativo alto frente a un $8 \%$ de los que provienen de hogares de clima educativo bajo. Esto supone una importante reproducción inter-generacional del capital educativo, por una parte y por otra se mantienen y agudizan las distancias intra-generacionales. No sólo la distribución en el nivel educativo alcanzado acusa serias desigualdades en función del clima educativo del hogar de origen, sino que también muestra diferencias en el tiempo requerido para aprobar la educación media. 


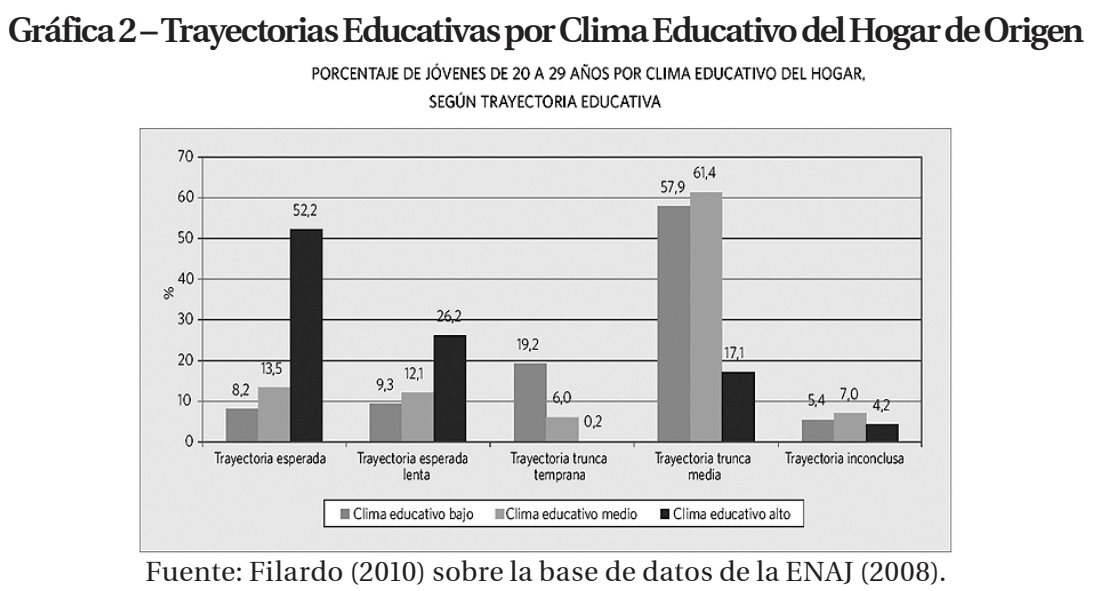

\section{Integralidad en el Análisis de Trayectorias Educativas}

Por lo que se ha mostrado antes, es deseable para los análisis de trayectorias educativas que éstas integren el recorrido por el sistema educativo en sus diferentes niveles. Los resultados por nivel educativo como si fueran espacios autónomos opaca los procesos de influencia sucesiva. Por eso se enfatiza en la construcción de trayectorias que integren el tránsito por los diferentes ciclos.

Sin embargo, otra dimensión de la integralidad es necesaria: el sistema educativo es uno de los espacios por los que transcurren los individuos pero no es el único. Simultáneamente ocurren otros eventos vitales, que impactan fuertemente en los itinerarios educativos. Por tanto, las políticas de educación deben responder a la lógica de la integralidad, compatibilizando el tránsito por el sistema educativo con otras transiciones (el ingreso al mercado laboral en forma estable; la salida del hogar de origen, el nacimiento del primer hijo, por ejemplo).

Varios antecedentes nacionales han demostrado que las transiciones hacia los diferentes roles considerados adultos (trabajador/a; madre o padre, etc.) ocurren a edades diferentes según la posición que se ocupe en la estructura social y que en particular ésta está asociada a los niveles educativos que se alcancen. (Filardo, 2010; 2012)

En la gráfica 3 se presenta el porcentaje acumulado de jóvenes (25 a 29 años) que a cada edad había experimentado los eventos: salida del sistema educativo; ingreso a un empleo estable, salida del hogar de origen y nacimiento del primer hijo. La gráfica permite visualizar la secuencia (el orden) que en términos agregados ocurren dichos eventos. Se han considerado los años 2008 y 2013, para estudiar la evolución en el periodo, a partir de dos (falsas) cohortes de nacidos (1979-1983 y 19841988). La elección de estas cohortes se fundamenta en que se pretenden estudiar los efectos que produce la generación en la ocurrencia de los eventos ${ }^{12}$. 
Integralidad en el Análisis de Trayectorias Educativas

Por otro lado, hay que tener en cuenta que el análisis es sobre los eventos ${ }^{13}$, es decir la ocurrencia por primera vez de un hecho que representa un cambio de estado del individuo (desempeño de un rol). Por ejemplo, la edad al primer hijo es independiente de la edad al momento del relevamiento. Si un individuo tiene el primer hijo a los 17 años, la respuesta queda fija si se le pregunta a los 20 o a los 40 años. Siempre será 17 años. En términos agregados, la proporción de jóvenes nacidos en 1980 que tuvieron el primer hijo a los 17 años será la misma para toda edad superior a 17 años en que se realice la medición. La ocurrencia de los eventos puede asociarse a efectos de edad, de cohorte (generación) o de periodo. En este caso, se pretenden relevar los efectos que produce la pertenencia a una generación respecto a otra (por eso deben ser diferentes), dejando fija la edad al relevamiento de los jóvenes. En la medida en que un sector de jóvenes relevados en la ENAJ 2008 y ENAJ 2013 pertenecen a las mismas cohortes de nacidos ${ }^{14}$, - aunque varíen sus edades en cada uno de los relevamientos -, el análisis en términos agregados no podría distinguir el efecto generación. Por este motivo sólo se consideran los que tienen entre 25 y 29 años en ambas encuestas (2008 y 2013) que pertenecen a cohortes de nacidos diferentes.

Para el total de los jóvenes que al momento de la encuesta tenían entre 25 y 29 años (ENAJ 2008 y 2013), la secuencia de los eventos es la misma en los dos años. El evento que se da más temprano es la salida del sistema educativo, luego la inserción en el mundo del trabajo, a posteriori la autonomía y más adelante aún en el tiempo el primer hijo. No obstante, tal como lo muestra la gráfica, en el 2013 se incrementa la edad de permanencia en el sistema educativo respecto al 2008, y aunque el ingreso al mercado laboral también se da más adelante en el tiempo, la distancia entre ambos eventos se acorta. A su vez, la autonomía marca una diferencia entre las dos cohortes analizadas a partir de los 18 años - el porcentaje acumulado es mayor en el 2013 -, mientras que se visualiza una postergación de la edad del primer hijo que se evidencia a partir de los 18 años. 
Gráfica 3 - Edad de ocurrencia de los eventos. Jóvenes de 25 a 29 años. 2008 y 2013 (en porcentajes acumulados)

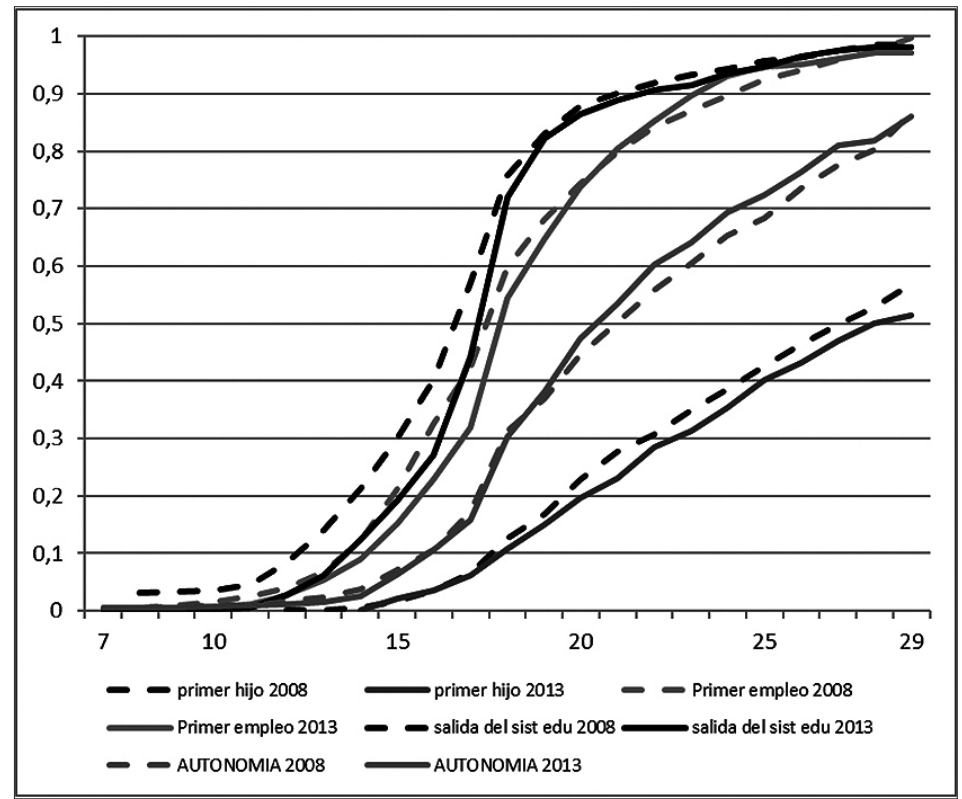

Fuente: ENAJ (2008); ENAJ (2013).

El nivel educativo alcanzado constituye uno de los indicadores más potentes para clasificar a los individuos según la posición que ocupan en la estructura social. Con el objetivo de mostrar que los diferentes trayectos educativos se acompañan de diferentes trayectos laborales, reproductivos y de autonomía, se utiliza el nivel educativo como variable de corte en el análisis. El nivel educativo alcanzado fue codificado en tres categorías: hasta primaria, educación media y terciaria. El criterio para la demarcación de las categorías es la aprobación de al menos un año en el nivel que se alcanza ${ }^{15}$. 


\section{Gráfica 4 - Edad de Ocurrencia de los Eventos Según Nivel Educativo Alcanzado, Jóvenes de 25 a 29 Años, 2008 y 2013 (en porcentajes acumulados)}

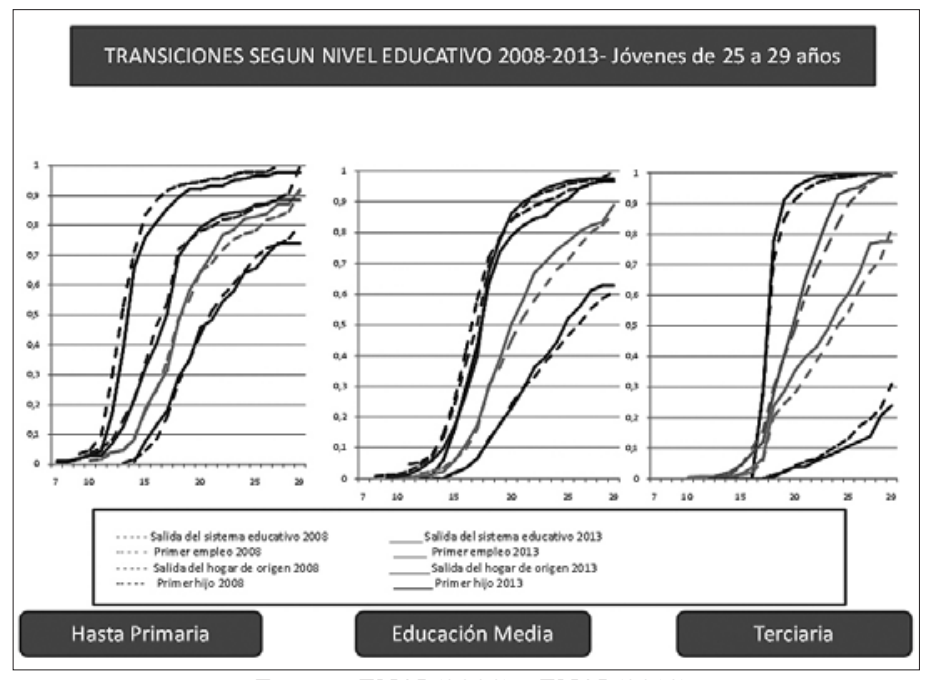

Fuente: ENAJ (2008) y ENAJ (2013).

El nivel educativo es un factor con alto poder de determinación en la intensidad y en el calendario de las transiciones ${ }^{16}$. Como se evidencia en las gráficas, no sólo todos los eventos ocurren más temprano entre los que cuentan con menores capitales educativos, sino que se concentran un lapso corto. En cambio, entre los que alcanzan la educación terciaria, ocurren a edades mayores y son más espaciados en el tiempo. Puede verse que la distancia que existe entre salir del ciclo medio y tener el primer hijo es la máxima entre los que alcanzan estudios terciarios. De hecho el bajo porcentaje de jóvenes con educación terciaria que han sido padres o madres por primera vez antes de los 30 años (menos del $30 \%$ ) sugiere que el inicio a la vida reproductiva entre los más educados ocurre en edades que los clasificarían como adultos/as. Se manifiesta una postergación de los proyectos familiares y reproductivos cuando los tránsitos educativos son de mayor duración, lo que también sugiere perspectivas temporales diferenciadas. (Leccardi; Rampazi, 1993; Leccardi, 2002; Filardo, 2013).

Al considerar el sexo de los individuos, (gráfica 7), se aprecia que: 1. La distancias entre la edad de salida del sistema educativo y de entrada al mercado laboral es mucho menor en varones que en mujeres tanto en el 2008 como en el 2013. Esto significa que los varones entran al mercado de trabajo más temprano que las mujeres, y que la trayectoria educativa compite con la trayectoria laboral en mayor medida (Filardo, $2010)^{17}$. Esta información es relevante para el diseño de políticas (o programas) educativas y de promoción del primer empleo para jóvenes. 2. El ingreso al mercado laboral en las mujeres de la cohorte que al 2013 
tiene entre 25 y 29 años muestra un comportamiento diferenciado según la edad relativo al 2008. Es levemente más temprano hasta los 18 años, y más tardío a partir de esta edad. En cambio, en los varones se aprecia una incorporación laboral más tardío en el 2013 que en el 2008 hasta los 23 años (el 93\% ha tenido un empleo estable) y a partir de esa edad no hay diferencias sustantivas con respecto al 2008. 3. El porcentaje acumulado por edad de varones que se autonomizan a partir de los 18 años es mayor en el 2013 que en el 2008. En las mujeres se mantiene un comportamiento similar en ambos relevamientos. 3. La postergación de la edad al primer hijo, entre el 2008 y el 2013, se da en mujeres; en los varones no presenta variaciones. 4. Las brechas por sexo en todos los eventos tienen a disminuir entre el 2008 y el 2013.

\section{Gráfica 5 - Edad de Ocurrencia de los Eventos Según Sexo, Jóvenes} de 25 a 29 Años, 2008 y 2013 (en porcentajes acumulados)

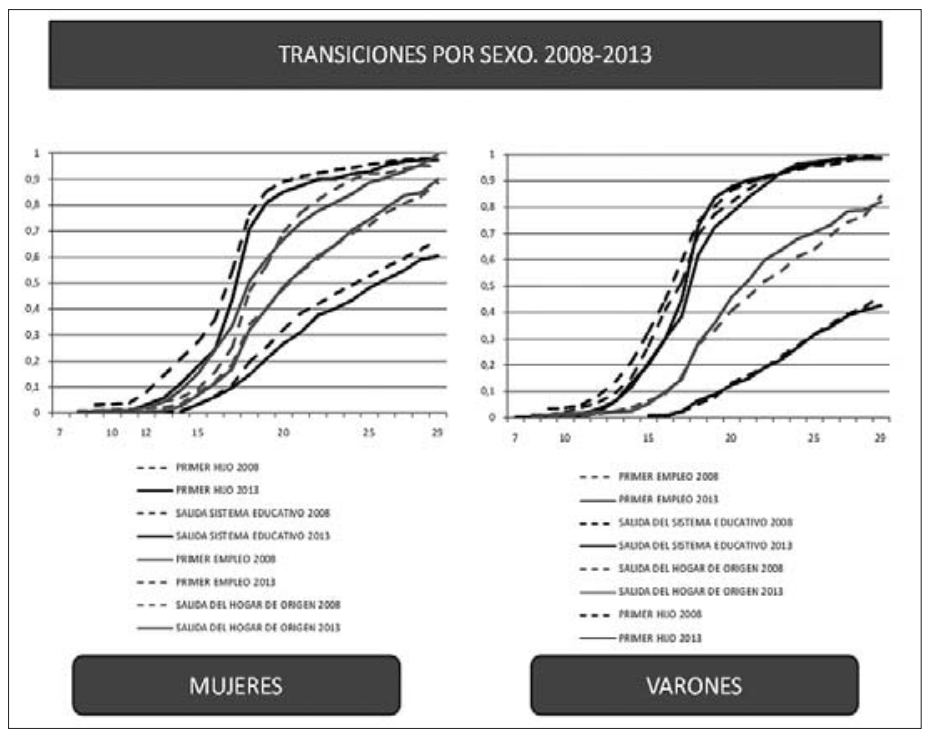

Fuente: ENAJ (2008) y ENAJ (2013).

Se presentan a continuación las gráficas por nivel educativo, para cada uno de los sexos. En estudios anteriores, al analizar la evolución 1990-2008, se mostró que las principales desigualdades entre los jóvenes en Uruguay se daban entre las mujeres según el nivel educativo alcanzado, y que la brecha aumentaba en el periodo considerado (Filardo, 2012), y por lo tanto es relevante ver qué sucede en el 2013, teniendo en cuenta que aquí sólo se consideran dos cohortes de nacidos (1979-1983 y 1984-1988). 
Gráfica 6 - Edad de Ocurrencia de los Eventos Según Nivel Educativo Alcanzado, Mujeres Jóvenes de 25 a 29 Años, 2008 y 2013 (en porcentajes acumulados)

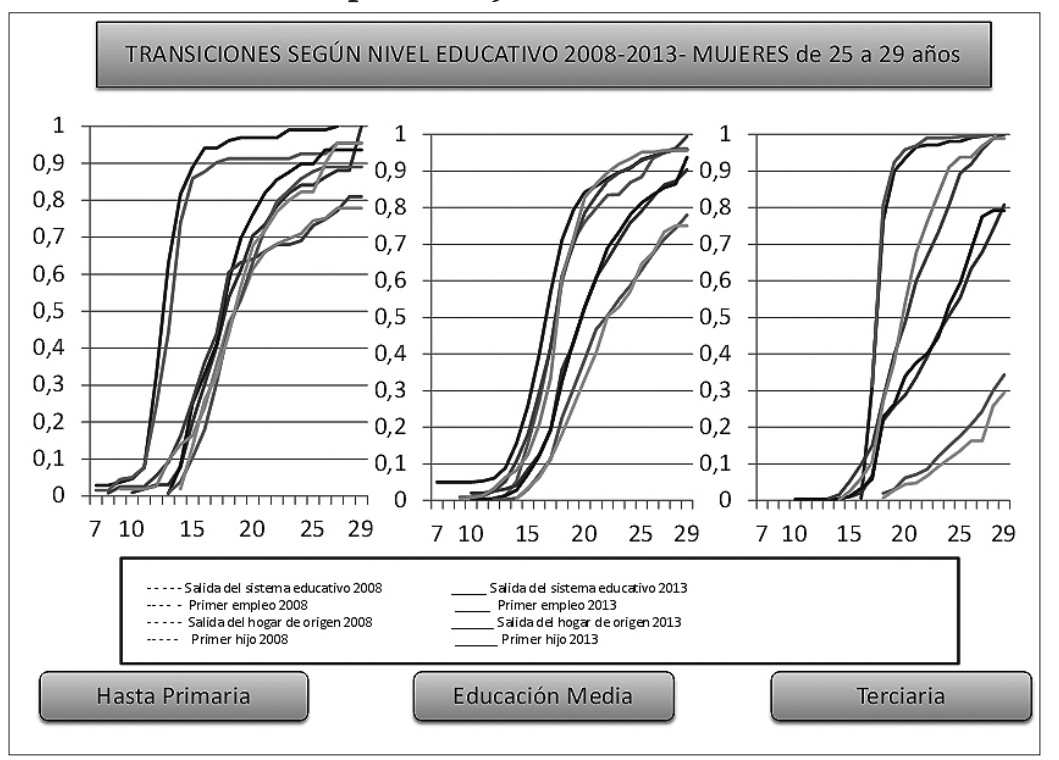

Fuente: ENAJ (2008) y ENAJ (2013).

Se encuentran grandes diferencias entre las mujeres de las cohortes estudiadas en el 2008 y 2013, en función del nivel educativo que alcancen, marcando que las dos variables consideradas juntas constituyen uno de los principales factores de desigualdad entre los jóvenes del Uruguay.

En primer lugar, se observa que los eventos varían en secuencia (en el orden en que se producen) y notoriamente en intensidad según se alcance hasta primaria o se haya al menos aprobado un año en el nivel terciario. Las que cuentan con menos escolarización muestran que a partir de los 19 años, el porcentaje de los que ha tenido el primer hijo supera (con diferencias relevantes) la proporción de las que han experimentado el primer empleo. La proporción de las que no se incorporan hasta los 29 años en el mercado laboral en la cohorte 2013 se mantiene, respecto al 2008, cercano al $20 \%$. Por otra parte, la salida del sistema educativo es un evento temprano y notoriamente anterior a los otros tres. La salida del hogar de origen, el primer empleo y el primer hijo son eventos prácticamente simultáneos, hasta los 20 años. Es a partir de esta edad que se incrementa a gran velocidad la proporción de mujeres con nivel educativo alcanzado hasta primaria que se autonomizan, y que tienen su primer hijo, mostrando un estancamiento en la proporción de las que ingresan al primer empleo.

El orden de los eventos aparece más claro en los otros dos niveles educativos, y en las que alcanzan educación terciaria los eventos 
Filardo

ocurren además, más distantes entre sí. En las mujeres que alcanzan educación media el ingreso al mercado de trabajo es anterior a partir de los 18 años respecto a la salida del sistema educativo en el 2013, lo cual sugiere que se incrementa en este sector el número de personas que estudian y trabajan, previo a la salida del sistema educativo en el ciclo medio.

Entre las que alcanzan educación terciaria, cerca del $90 \%$ culmina el ciclo medio en la edad prevista para ello, continuando con trayectoria educativa. La postergación de los otros tres eventos es notoria en relación a las mujeres que alcanzan menor escolarización, particularmente el tener el primer hijo (no alcanzan a ser el $30 \%$ a los 29 años).

Debe notarse que las distancias que se verifican entre las mujeres que tienen entre 25 y 29 años en el 2008 y el 2013 se incrementan. Esto está dado particularmente porque la edad al primer hijo se retrasa en las que alcanzan educación terciaria, mientras la de menor escolarización describe curvas similares. De forma similar la intensidad del primer empleo aumenta a partir de los 20 años en las de educación terciaria de la cohorte del 2013, respecto a la estudiada de 2008. Por tanto las desigualdades entre las mujeres, según su nivel educativo, siguen aumentando en el periodo 2008-2013, manteniendo la tendencia registrada entre 1990-2008 (Filardo, 2012).

Gráfica 7 - Edad de Ocurrencia de los Eventos Según Nivel Educativo Alcanzado, Jóvenes Varones de 25 a 29 Años, 2008 y 2013 (en porcentajes acumulados)

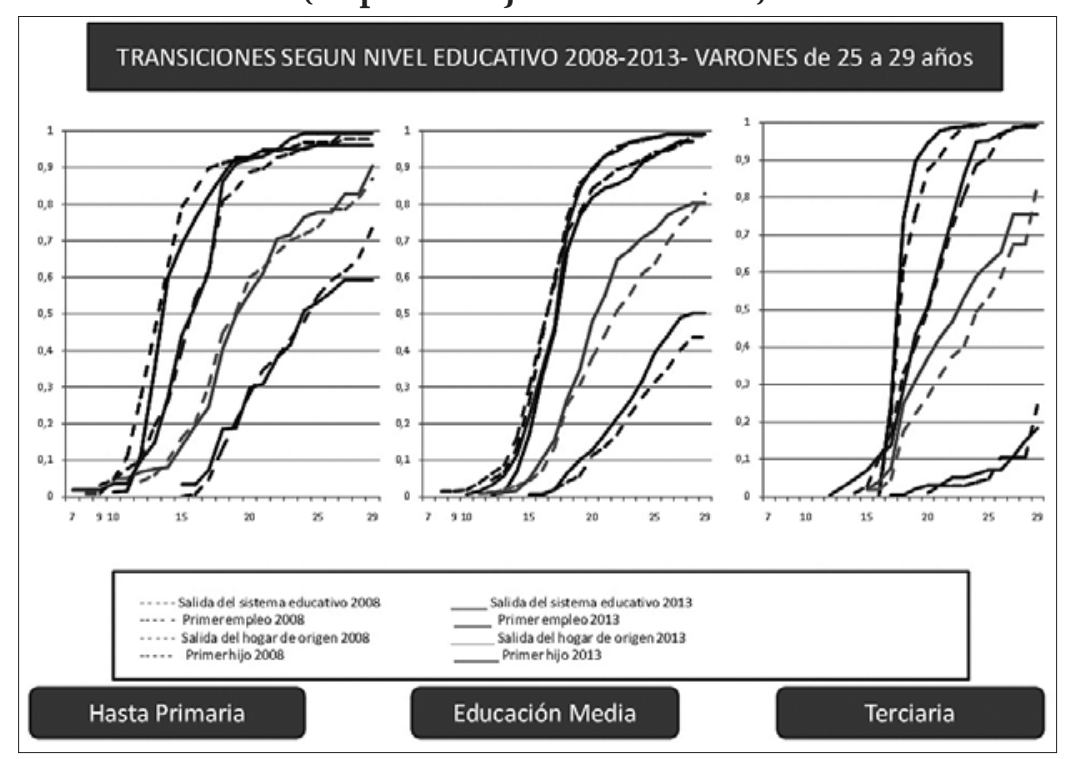

Fuente: ENAJ, 2008 y ENAJ, 2013.

En los varones, si bien el nivel educativo alcanzado no altera la secuencia de los eventos entre el 2008 y el 2013 (salvo para los de educa- 
Integralidad en el Análisis de Trayectorias Educativas

ción media en que a partir de los 18 años el ingreso al mercado laboral es más temprano que la salida del sistema educativo), se produce una traslación de las curvas en las edades a medida que se avanza en los niveles educativos. Las transiciones son más tardías entre los más educados. Si bien la intensidad a los 29 años es similar en los tres niveles educativos, excepto en el evento primer hijo, que registra a esa edad el $60 \%$ de los que alcanzan hasta primaria y el $18 \%$ de los que aprueban al menos un año de estudios terciarios.

Las gráficas permiten visualizar que el comportamiento de los varones difiere menos que entre las mujeres por nivel educativo. A su vez la autonomía de los varones crece en todos los niveles educativos respecto al 2008.

En el 2008 se había señalado que las curvas que representaban la proporción acumulada por edad al primer empleo y salida del sistema educativo de los varones que alcanzaban nivel educativo medio eran prácticamente superpuestas. En el 2013, se presenta también criticidad en este sector de varones por la proximidad de las curvas de ambos eventos hasta los 18 años; incluso a edades mayores la proporción de los que ingresan al primer empleo supera a los que salen del sistema educativo. Esto sostiene - al igual que lo que ocurre con las mujeres - que probablemente desempeñen los dos roles de forma simultánea - trabajador y estudiante - o tengan recorridos intermitentes en ambas trayectorias. En todo caso, el sistema educativo presenta una mayor retención en el 2013 que en el 2008.

\section{Trayectorias Truncas Medias: motivos dados por los jóvenes en Chile, Costa Rica y Uruguay}

La necesidad de la integralidad en el estudio de las trayectorias educativas - aludiendo a los efectos recíprocos que éstas sostienen con otras dimensiones vitales - se manifiesta cuando, por ejemplo, se analizan las respuestas que los jóvenes dan frente a los motivos que ellos mismos atribuyen a haberse desvinculado del sistema educativo antes de culminar el nivel medio.

A partir de la información proveniente de las Encuestas Nacionales de Juventud que realizan tres países de la región (Chile, Costa Rica y Uruguay $)^{18}$ se manifiesta la relevancia que tienen los eventos ingreso al mercado de trabajo, embarazo, cuidados familiares frente a los factores de oferta y/o institucionales, es decir, aquellos que responderían al propio sistema educativo, diseño de planes curriculares o aspectos pedagógicos (falta de interés, te resultaba difícil).

Las gráficas que se presentan a continuación muestran el nivel educativo alcanzado por aquellos jóvenes que al momento de la encuesta se encuentran desafiliados del sistema educativo en los tres países, desagregadas por tramo de edad. Se aprecian distribuciones diferen-

30 Educação \& Realidade, Porto Alegre, v. 41, n. 1, p. 15-40, ene./mar. 2016. 
tes en los países. En Chile al momento de la desafiliación del sistema, un $54 \%$ había alcanzado educación secundaria y un $42 \%$ primaria. En el Uruguay los porcentajes son similares, 51\% y $49 \%$ respectivamente. Costa Rica marca un porcentaje mayor de jóvenes de estas edades que no estudian y sólo alcanzaron primaria como máximo nivel educativo (75\%), lo que señala un truncamiento temprano de las trayectorias educativas de los jóvenes de este país. En el tramo de edad de 18 a 24 años, se aprecia que: en Chile el 19\% alcanzó nivel terciario, frente al $8 \%$ en Costa Rica y el 5\% en Uruguay. En el otro extremo, entre quienes solo alcanzaron primaria como máximo nivel educativo, el mayor porcentaje lo registra Costa Rica con un $46 \%$, seguido de Uruguay con $15 \%$ y Chile con un $11 \%$. Esto señala que la situación más crítica en cuanto al nivel de escolarización de la población desafiliada del sistema está en el país centroamericano, lo cual por otro lado sugiere una polarización educativa, dado que cerca de la mitad de los jóvenes que no estudian no superan primaria ${ }^{19}$.

\section{Gráfica 8}

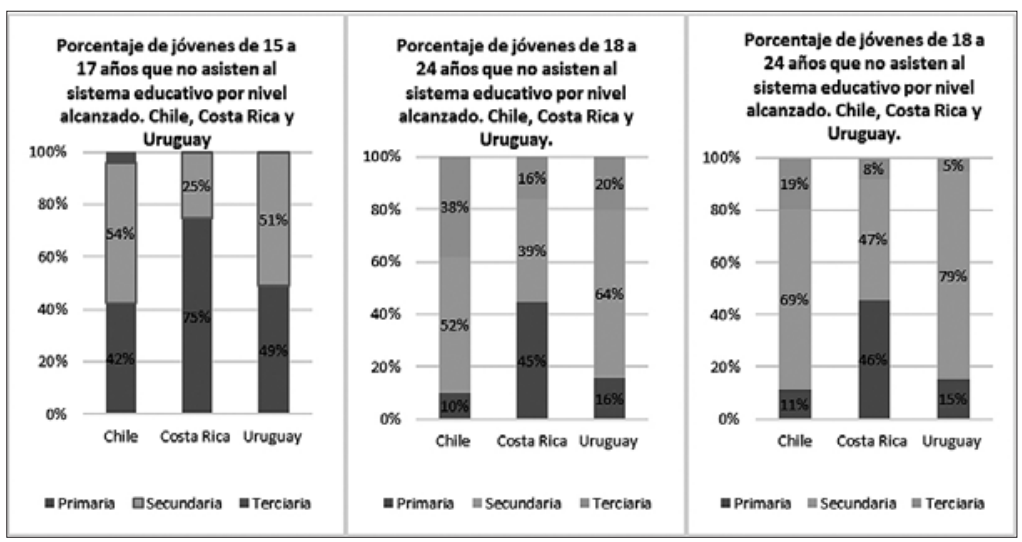

Fuente: elaboración propia en base a ENJ, Costa Rica 2013, ENJ, Chile 2012, ENAJ Uruguay 2013.

Entre los 25 y 29 años, se mantiene esta tendencia en Costa Rica, ya que cerca de la mitad (45\%) no superan el nivel primario, frente al $10 \%$ de Chile y $16 \%$ de Uruguay. El nivel medio o secundario sugiere mayores problemas para su continuidad en Uruguay: el 64\% de los jóvenes que no estudian actualmente se desafilian en ese nivel educativo; frente a un $52 \%$ en Chile y $39 \%$ en Costa Rica. Vale recordar que en Chile y Uruguay son 14 años de educación formal obligatoria, mientras en Costa Rica son 11 años, desde preescolar hasta tercer año de secundaria ${ }^{20}$. Asimismo el 38\% de los jóvenes de este tramo etario desafiliados del sistema en Chile alcanzaron estudios superiores, frente a un $16 \%$ de los de Costa Rica y $20 \%$ de Uruguay.

Uno de los aportes específicos de las encuestas nacionales de juventud que se utilizan como fuente de información es contar con los 
motivos que los mismos jóvenes atribuyen a su deserción educativa. Debe considerarse que sólo se consideran aquellos que no asisten a un centro de educación formal, pero que no egresaron del nivel ${ }^{21}$. Si bien las tres encuestas registran motivos para la no asistencia, las preguntas utilizadas, así como las categorías de respuestas difieren entre los tres relevamientos; por lo que se elabora una armonización de las distintas preguntas en una única variable ${ }^{22}$.

Tabla 1 - Distribución porcentual de los motivos para no asistir a establecimientos de educación formal. Jóvenes de 15 a 29 años que no han terminado educación media

\begin{tabular}{|c|c|c|c|}
\hline & Chile & $\begin{array}{c}\text { Costa } \\
\text { Rica }\end{array}$ & Uruguay \\
\hline No le interesa & 12,6 & 11,1 & 31,4 \\
\hline Empezó a trabajar & 24,7 & 37,7 & 33,9 \\
\hline Es difícil & 1,7 & 3,4 & 10,4 \\
\hline Problemas económicos & 23,8 & 12,5 & 4,9 \\
\hline $\begin{array}{c}\text { Embarazo (propio o de su pareja)y/o debió } \\
\text { atender asuntos familiares }\end{array}$ & 28,7 & 25,1 & 13,2 \\
\hline Otros & 8,5 & 10,2 & 6,2 \\
\hline Total & 100,0 & 100,0 & 100,0 \\
\hline
\end{tabular}

Fuente: Elaboración propia en base a ENJ, Costa Rica 2013, ENJ, Chile 2012, ENAJ Uruguay 2013.

Se observan diferencias relevantes entre los países en relación a los motivos que dan los jóvenes para su desafiliación educativa. En Chile los porcentajes mayores se ubican en embarazo o debió atender asuntos familiares (29\%) y Problemas económicos (24\%); en Costa Rica empezó a trabajar $^{23}$ (38\%) y embarazo o debió atender asuntos familiares (25\%), mientras que en Uruguay las respuestas se concentran en empezó a trabajar (34\%) y no le interesa (31\%). De lo anterior surgen especificidades nacionales; los problemas situados en la oferta aparecen en Chile como síntoma de un sistema que requiere pago de parte de las familias, y que se refleja en la respuesta problemas económicos; en cambio en Uruguay, que sostiene un sistema de acceso universal gratuito, indica una propuesta curricular poco atractiva y eventualmente expulsora que denota la respuesta no tenía interés ${ }^{24}$.

Asimismo, tanto en Chile como en Costa Rica, embarazo y tener que atender asuntos familiares son uno de los principales motivos dados por los jóvenes; mientras en Uruguay este motivo es aducido por un porcentaje de jóvenes sustantivamente menor. Como se ha visto en el apartado anterior - utilizando técnicas de historia de eventos - la curva que representa el porcentaje acumulado por edad de los que han experimentado la salida del sistema educativo se distancia de la que representa el porcentaje que ha tenido su primer hijo; mostrando que la deserción educativa es anterior al primer hijo (Filardo, 2010; 2013). Por 
otra parte, como se observa en la gráfica 8 , la proporción de jóvenes que tienen hijos en cada tramo de edad marca diferencias relevantes en los tres países.

Gráfica 9 - Porcentaje de Jóvenes por Tramo de Edad que Tienen Hijos al Momento de la Encuesta: Chile, Costa Rica y Uruguay (2012-2013)

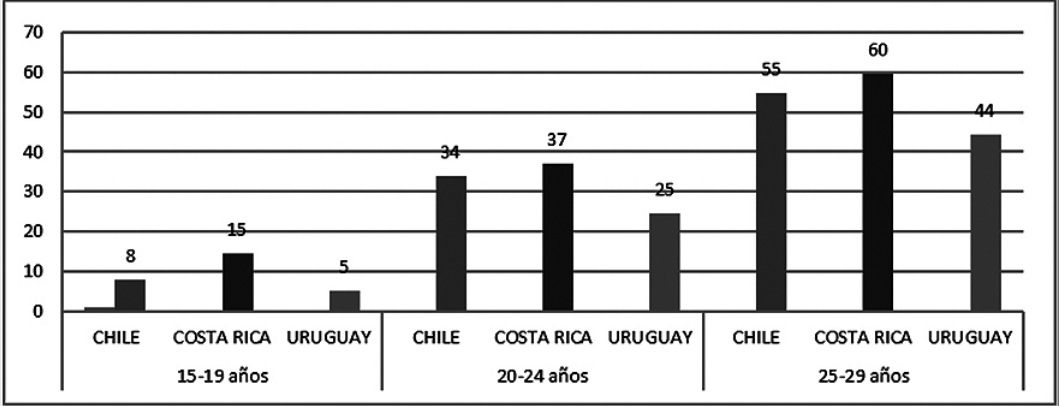

Fuente: Elaboración propia en base a ENJ, Costa Rica 2013, ENJ, Chile 2012, ENAJ Uruguay 2013.

Los motivos que esgrimen los jóvenes para no asistir a educación formal presentan asociación tanto con el sexo como con la edad de los encuestados. El principal motivo para no asistir mencionado por los varones de los tres países estudiados es el haber comenzado a trabajar; $59 \%$ de los jóvenes de Costa Rica, $43 \%$ de los uruguayos y $38 \%$ de los chilenos. Para las mujeres de Costa Rica y Chile el principal motivo para no asistir es embarazo y/o atender a asuntos familiares, con un 50\% y 44\% respectivamente. En las jóvenes uruguayas el principal motivo para la no asistencia es la falta de interés (28\%), seguido por embarazo y/o atender asuntos familiares con un $25 \%{ }^{25}$. En el caso chileno, donde los motivos económicos registran valores altos como argumento para la no asistencia, se observa independencia en la incidencia según sexo.

\section{Gráfica 10 - Distribución Porcentual de los Motivos para No Asistir a Centros de Educación Formal por Sexo, Jóvenes de 15 a 19 Años que No Han Terminado Educación Media}

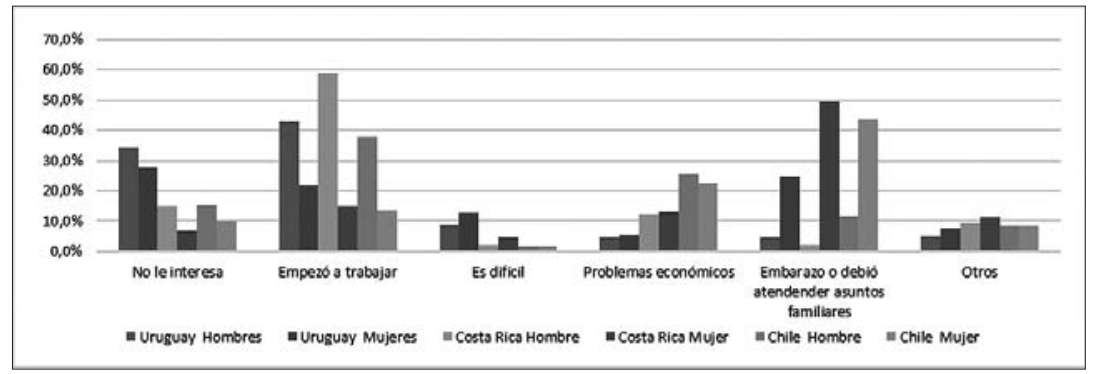

Fuente: Elaboración propia en base a ENJ, Costa Rica 2013, ENJ, Chile 2012, ENAJ Uruguay 2013. 
Gráfica 11 - Distribución Porcentual de los Motivos para no Asistir a Centros de Educación Formal por Tramos de Edad, Jóvenes de 15 a 19 Años que no Han Terminado Educación Media

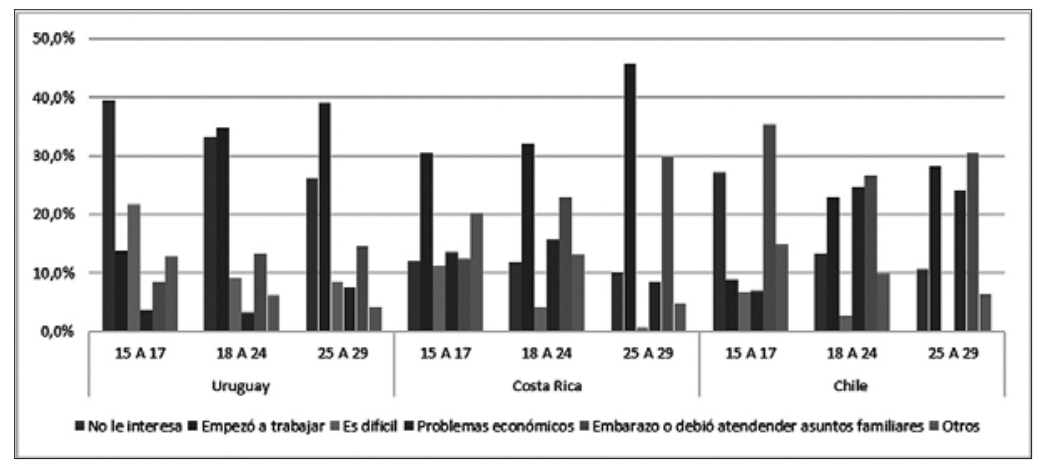

Fuente: Elaboración propia en base a ENJ, Costa Rica 2013, ENJ, Chile 2012, ENAJ Uruguay 2013.

$\mathrm{Al}$ analizar los motivos de no asistencia por tramos de edad se destaca que en Chile, para los tres tramos de edad, el principal motivo para la no asistencia es el embarazo y/o el deber atender asuntos familiares. El mismo asume un $35 \%$ en el tramo de 15 a 17, un $27 \%$ en el de 18 a 24 y un $31 \%$ en el de 25 a 29.

Un segundo aspecto que debe subrayarse es el hecho de que en Chile y en Uruguay se presentan valores relativamente altos en la respuesta No le interesa; $40 \%$ y $27 \%$ respectivamente para el tramo de 15 a 17 años. En particular para el Uruguay es la categoría con porcentaje más alto en este tramo. En Costa Rica el principal motivo para haber abandonado los estudios en estas edades es el haber comenzado a trabajar que registra un $30 \%$; el valor se mantiene estable para el tramo de 18 a 24 años. En Uruguay, en el tramo de 18 a 24 años el principal motivo para la desvinculación del sistema educativo es el haber comenzado a trabajar con un $35 \%$. Chile es, de los tres países, el que presenta porcentajes más bajos en esta categoría para el tramo de 18 a 24 años.

Los problemas de la oferta educativa en el nivel medio se manifiestan relevantes para interpretar las dificultades de retención de los sistemas educativos, y para las trayectorias educativas, particularmente en Chile (requiere el pago de las familias) y en Uruguay (la ausencia de interés que despierta en los jóvenes la propuesta curricular). Asimismo, la continuidad o truncamiento de la trayectoria educativa está en gran medida asociada a la ocurrencia de otros eventos, que se vinculan con la transición a la adultez (Casal, 1996): el ingreso al mercado laboral, el inicio de la vida reproductiva, la convivencia en pareja y la autonomía (salida del hogar de origen o neolocalismo). Esto sugiere que las medidas que se orienten a favorecer la permanencia en el sistema educativo no pueden aislarse en la esfera educativa y acotarse a lo sectorial. En la vida 
de los jóvenes se intersectan diferentes planos, produciendo impactos recíprocos. La integralidad de las acciones, en consecuencia, implica considerar los tránsitos en distintas dimensiones de la vida. Desempeñar el rol de trabajador/a en el mercado de empleo, en forma remunerada, compite con la continuidad en el sistema educativo concentrando las respuestas del motivo principal para la deserción en Uruguay y Costa Rica. El inicio temprano de la vida reproductiva, particularmente para las mujeres, adquiere magnitud sustantiva en Costa Rica, y en menor medida en Chile. Asimismo existe abundante documentación sobre la fecundidad más temprana en los sectores populares, lo que probablemente incremente las desigualdades en las generaciones siguientes.

\section{Notas Finales}

Se proponen dos vectores analíticos para trabajar las trayectorias educativas. El primero alude a la necesidad de construir las trayectorias integrando los resultados de los diferentes ciclos o niveles educativos. Los resultados que se obtengan en uno, tienen efectos en los siguientes. A pesar de lo simple de esta idea, con frecuencia los estudios sobre resultados educativos se acotan a cada nivel sin integrar los anteriores, como si fueran completamente autónomos unos de otros. De hecho en Uruguay, el sistema de información educativa (a partir de registros administrativos) no cuenta aún con la posibilidad de integrar los resultados individuales en los diferentes ciclos. Es por esto que para poder hacerlo se utiliza como fuente la ENAJ (2008), que construye datos retrospectivos de cada encuestado sobre su trayectoria educativa ${ }^{26}$.

Desde esta premisa se presenta la tipología de trayectorias educativas, considerando el nivel educativo alcanzado y el tiempo requerido para ello. A partir de los tipos de trayectorias, se muestra que la repetición en el nivel primario ${ }^{27}$ tiene un peso significativo en determinar la probabilidad de egreso de Educación Media. En consecuencia, el asunto educativo merece re-colocarse: no es sólo un problema de Educación Media, si bien se expresa en ese ciclo. En 2008 en Uruguay, el 10\% de los jóvenes que inician Educación Media con extraedad logran completar el nivel. En el conjunto de jóvenes de 20 a 29 años son el 1\% y corresponden al 3\% de los que finalizan Educación Media. Como es obvio, el $97 \%$ de los que aprueban el nivel medio de educación no repitieron en el ciclo primario.

La repetición en Primaria se constituye así en un problema extremadamente serio. Las autoridades educativas hace décadas que implementan diferentes medidas intentando disminuir su incidencia (Peri, 2008). Sin embargo la repetición no ha sido abolida como dispositivo y en consecuencia como resultado posible. Se encuentra instalado en la cultura institucional de la escuela y aunque registra fluctuaciones, tiende a regresar a una media del orden del 25\% del total de la población que experimenta al menos un año de repetición en Primaria. Las tasas

Educação \& Realidade, Porto Alegre, v. 41, n. 1, p. 15-40, ene./mar. 2016. 
Integralidad en el Análisis de Trayectorias Educativas

de repetición escolar del Uruguay son desde hace más de una década de las más altas de América Latina (Cardozo, 2008) ${ }^{28}$.

Asimismo las trayectorias educativas son útiles para el análisis de las inequidades o desigualdades sociales. Se distribuyen diferencialmente por sexo, por clima educativo del hogar de origen ${ }^{29}$. También son de utilidad para estudiar si determinada trayectoria educativa se vincula a ciertos resultados en el mercado de trabajo por ejemplo ${ }^{30}$.

El segundo vector sobre el que se enfoca en este trabajo es sobre la integralidad necesaria en las políticas educativas, aludiendo a que el tránsito por el sistema educativo es uno de los espacios por los que transcurre la vida de los jóvenes pero no el único. A partir de diferentes técnicas se establece la secuencia en que se producen los eventos que indican el inicio o fin de desempeño de roles que son considerados habitualmente en los análisis de transiciones a la adultez (salida del sistema educativo, ingreso al mercado de trabajo, inicio de la vida reproductiva y autonomía del hogar de origen) ${ }^{31}$. El orden en que se dan los eventos y la cercanía o distancia en el tiempo (la edad en que ocurren) muestra que las trayectorias educativas de los individuos tienen impactos recíprocos con otras relativas a distintas dimensiones. Es relevante porque ello evidencia comportamientos, proyectos de vida y perspectivas temporales diferenciadas que muestran la fragmentación en los mundos juveniles actuales en el Uruguay. Asimismo, el análisis de la evolución (2008-2013) permite mostrar que la distancia entre esos mundos se incrementa en el periodo y que en consecuencia se presentan síntomas de fractura.

Por último, la comparación de los resultados de las respuestas que dan los jóvenes de Costa Rica, Chile y Uruguay sobre los motivos por los cuales abandonaron los estudios en el nivel medio sin completarlo (quienes recorren trayectorias trunca media), al inicio de la primer década del siglo XXI, señala varios elementos: en primer lugar la relevancia de la integralidad aludida en los párrafos anteriores, dado que en los tres países se muestra que la desvinculación del sistema educativo se atribuye en un porcentaje elevado (aunque diferente en los tres casos) a los eventos trabajar, constituir su familia (con las cargas correspondientes) e iniciar la vida reproductiva. En segundo lugar, los factores institucionales (vinculados a la oferta, a los planes y a los dispositivos pedagógicos) e individuales (asociados al desempeño de otros roles que dificultan la continuidad en el rol de estudiante) como motivos de desvinculación del sistema educativo tienen pesos diferentes en los tres países, lo que permite ver particularidades nacionales.

Recibido en 30 de mayo de 2015 Aprobado en 21 de noviembre de 2015

36 Educação \& Realidade, Porto Alegre, v. 41, n. 1, p. 15-40, ene./mar. 2016. 


\section{Notas}

1 Los 14 años de educación formal obligatoria corresponden a dos años de educación inicial, seis de educación primaria, tres de educación media básica y tres de educación media superior.

2 Encuesta Nacional de Adolescencia y Juventud (2008) llevada adelante por INFAMILIA-INJU-MIDES, considerando como población a los jóvenes que residen en hogares particulares en centros poblados de todo el territorio nacional de más de 5000 habitantes.

3 Según la Encuesta Continua de Hogares, aprueban el nivel medio el $38 \%$ en el 2008 y el $41 \%$ en el 2013 de los jóvenes urbanos de entre 20 y 29 años del Uruguay.

4 Debe notarse que para las trayectorias construidas aquí no se toma en cuenta la continuidad o no de estudios de nivel terciario (universitario o no universitario).

5 El sistema de información educativa de Uruguay no permite aún la construcción de trayectorias individualizadas que integren los diferentes niveles educativos. Esta tipología puede construirse con la ENAJ 2008 porque tiene información retrospectiva individual, declarada por los encuestados. Incluye asimismo al sector público y el privado y es la única fuente de información de alcance nacional que lo permite actualmente. Para este trabajo se decide no presentar los datos provenientes de la ENAJ 2013, dado que la información que arroja sobre resultados educativos no es congruente con otras fuentes oficiales. Se estima que no supone una alteración al propósito establecido: presentar el dispositivo metodológico construido para mostrar la determinación que los resultados de un nivel educativo ejercen sobre la probabilidad de egresar del siguiente.

6 En el 2008, del total de los jóvenes de entre 20 a 29 años, el 97,5\% finaliza el nivel.

7 Casi el 90\% de los jóvenes del tramo de 20 a 29 años en el 2008 se matriculan en Educación Media. Esto significa que en términos de acceso, la cobertura es muy alta, y al menos para el inicio del nivel puede asegurarse la igualdad de oportunidades.

8 Esta variable es construida a partir del promedio de años de educación formal de madre y padre, o tutores, madre y cónyuge (si es jefe de hogar y si corresponde). Se categoriza en: bajo si los años de educación formal promedio es 6 o menos; medio si el promedio de los años de educación formal varía entre 7 y 12; y alto si es superior a 13 años. Los datos provienen de la ENAJ, 2008.

9 Este hallazgo no es novedoso porque la investigación educativa nacional ha hecho hincapié en él en forma reiterada desde los estudios de CEPAL a comienzos de los años '90, pero continúa impactando como muestra contundente de inequidad en el país.

10 Sin embargo, estos mejores rendimientos y desempeños de las mujeres en el sistema educativo no se traducen en el mercado laboral. Si bien es cierto que a mayor nivel educativo alcanzado los ingresos percibidos por trabajo se incrementan al interior de cada uno de los sexos, para un mismo nivel educativo los ingresos percibidos (valor hora) es menor para las mujeres y la brecha es sostenida a lo largo del tiempo. El mercado laboral no valoriza de igual forma para mujeres y para varones los años de escolaridad alcanzados, ni el desempeño en el sistema, considerando como indicador el tiempo dedicado para alcanzar un mismo nivel: para las mujeres rinde menos que para los varones (Filardo, 2011).

11 Esta variable es construida a partir del promedio de años de educación formal de madre y padre, o tutores, madre y cónyuge (si es jefe de hogar y si corres-

Educação \& Realidade, Porto Alegre, v. 41, n. 1, p. 15-40, ene./mar. 2016. 
Integralidad en el Análisis de Trayectorias Educativas

ponde). Se categoriza en: bajo si los años de educación formal promedio es 6 o menos; medio si el promedio de los años de educación formal varía entre 7 y 12; y alto si es superior a 13 años. Los datos provienen de la ENAJ, 2008.

12 La cohorte de nacimiento es un indicador de generación si por ésta se entiende aquellos que se socializan en el mismo contexto socio-histórico a las mismas edades. Para ver diferencias entre generaciones, deben considerarse cohortes de nacidos diferentes. Si el tramo de edad considerado en este estudio fuera 20 a 29 años para las dos encuestas (2008 y 2013), se consideraría la cohorte de nacidos entre 1984 y 1988 en los dos relevamientos; en el 2008 estaría comprendido en el tramo de 20 a 24 años y en el 2013 en el tramo de 25 a 29 años. Por esta razón se consideran los jóvenes que tienen entre 25 y 29 años en ambas encuestas, que pertenecen a cohortes de nacidos distintas, permitiendo distinguir los efectos producto de la edad y los de la generación.

13 Por evento se entiende un hito en la vida de un individuo. Es el momento en que se ingresa al desempeño de un rol social considerado propio de la adultez. Se toma siempre la primera vez y por tanto se manifiesta como una marca que se registra a una edad determinada. En cambio, por estado se considera la situación en la que se encuentra un individuo al momento del relevamiento. Entonces, por ejemplo, la edad de ocurrencia del evento que corresponde a la transición al trabajo es a la que un individuo empieza a trabajar (ocupa un empleo estable, con una duración mayor a tres meses) y el estado es si el individuo se encuentra ocupado o no al momento de ser encuestado. Eso significa que el individuo puede estar en diversos estados en diferentes momentos, pero el evento (primer empleo) ocurre solo una vez en la vida. La edad en que se registra un evento es relevante tanto para el individuo, como en términos agregados. Los calendarios de los eventos de transición a la adultez enfocan en las edades de ocurrencia de dichos eventos para diferentes grupos sociales, e indican pautas de comportamiento, actitudinales, proyectos de vida y temporalidades diferentes, eventualmente manifiestan (o son expresión de) desigualdades (Filardo; Planel; Napilotti, 2012; Filardo; Planel, 2012).

14 Las encuestas relevan a diferentes edades al momento de la aplicación a individuos de las cohortes de nacidos entre 1984-1988; 1989-1993 y 1994-1998.

15 Así, los que son clasificados en educación terciaria deben haber aprobado un año en dicho nivel. Los que alcanzan educación media deben tener aprobado el primer año de Ciclo básico, caso contrario, se asignan en el nivel educativo hasta primaria. Agradezco a Mariana Cabrera su contribución para la construcción de esta variable en el 2013, que permite la comparación con la ENAJ, 2008.

16 Acusa mayores diferencias que la región de residencia y sexo por ejemplo (Filardo, 2015).

17 A partir de la superposición de las curvas del porcentaje acumulado por edad de los varones en la ocurrencia de los eventos ingreso al mercado laboral y salida del sistema educativo - lo que indica que ambos eventos ocurren simultáneamente - se argumentaba que el ingreso al primer empleo comprometía la trayectoria educativa. En el 2008 el $20 \%$ de los varones y el $13 \%$ de las mujeres de 25 a 29 años que habían abandonado el sistema educativo sin culminar la educación media declara que el motivo fue comenzar a trabajar. En el 2013 el principal motivo para dejar de estudiar en el nivel medio por comenzar a trabajar representa al 50,7\% de los varones y al 32,7\% de las mujeres.

18 ENJ, Costa Rica 2013, ENJ, Chile 2012, ENAJ Uruguay 2013.

19 Una de las interpretaciones posibles de este fenómeno es el flujo de inmigrantes con síntomas de vulnerabilidad y situaciones críticas de pobreza y bajos

38 Educação \& Realidade, Porto Alegre, v. 41, n. 1, p. 15-40, ene./mar. 2016. 
niveles educativos provenientes de otros países centroamericanos que Costa Rica recibe y que se concentran en el norte del país.

20 Esto según lo establecido en la Ley 7676 del año 1997, que reformó el artículo 78 de la Constitución Política de la República de Costa Rica.

21 Los que no asisten pero egresaron del nivel se excluyen del análisis.

22 Para mayor información respecto a la armonización puede consultarse Filardo y Borrás (2015).

23 Dado el alto porcentaje de los que han abandonado los estudios y solo alcanzan primaria como nivel educativo, es razonable pensar que el ingreso al mercado laboral de los jóvenes en Costa Rica sea más temprano que en los otros dos países.

24 Debe señalarse que esta opción como motivo principal registra, para el caso de Uruguay, más de 20 puntos porcentuales por encima de los valores de Chile y Costa Rica.

25 Es importante notar la amplitud de situaciones que reviste esta respuesta. Las tareas de cuidado asignadas según el modelo tradicional de género, a las mujeres, pueden asociarse a los hijos pero también a hermanos e incluso padres u otros familiares.

26 Vale a aclarar que las restricciones para ello no se ubican en lo técnico. Es necesario reconocer, no obstante, los esfuerzos realizados en tal sentido por lo que es probable que den frutos en los próximos años.

27 En Uruguay en el 2008, son más de uno de cada cinco jóvenes entre 20 y 29 años que en el 2008 habían experimentado al menos un año de repetición en este nivel.

28 No todos los países tienen el dispositivo de repetición en sus sistemas educativos. Uno de los debates más fuertes que se presentan entre las autoridades y los técnicos de la educación nacional se vincula a la pertinencia de mantenerlo o de eliminarlo como resultado posible de evaluación del año escolar.

29 También se acusan diferencias según región de residencia de los jóvenes, tercil de ingresos de sus hogares y tipo de institución educativa (sector público o privado) (Filardo, 2010). Asimismo se han estudiado los pesos específicos de diferentes variables predictoras en la determinación de la probablidad de tener una trayectoria trunca media (desvincularse del sistema educativo sin terminar la Educación Media, habiéndose matriculado en este nivel) (Filardo, 2010).

30 Se ha estudiado la relación entre la trayectoria educativa y el valor hora de trabajo remunerado entre aquellos jóvenes que están ocupados al momento de la encuesta (Filardo, 2010).

31 Es relevante señalar que las generaciones de los jóvenes contemporáneos, a diferencia de generaciones anteriores, no tienen puntos de llegada normativos ni normados. En el orden de las decisiones y futuros probables, existe una variada gama de opciones, difícilmente aceptadas en otros momentos históricos. Esto significa que en la actualidad, la decisión sobre tener hijos, puede (y cada vez lo es con mayor frecuencia) postergarse en el tiempo; e incluso puede decidirse no tenerlos, lo que era menos probable en el repertorio conductual en épocas pasadas. Otra de las características que se da más frecuentemente en la sociedades contemporáneas es la reversibilidad de los estados: puede abandonarse el sistema educativo y retomarse los estudios en momentos posteriores, tanto como pasar por diversos estados en relación a la condición de actividad y desocupación (entrar y salir del mercado de trabajo, estar ocupado o desocupado); al hogar en que se viva (ir a vivir solo o con pareja 
Integralidad en el Análisis de Trayectorias Educativas

y retornar al hogar de origen en caso de separación) y respecto a la situación conyugal (convivir o no en pareja). El menos reversible de todos los estados es el desempeño del rol de madre/padre. En este caso, una vez que ocurre el evento (tener el primer hijo) determina el desempeño del rol de madre/padre para el resto de la vida. Aún en éste puede percibirse una diferencia de género relevante en las implicancias que tiene en cuanto al impacto del desempeño del rol en el resto de las dimensiones vitales de los individuos.

\section{Referencias}

ANEP. Uruguay en PISA 2012: Programa Internacional de Evaluación de Estudiantes de la OCDE. Montevideo: 2013. Disponible en: <http://www.anep.edu. uy/anep/phocadownload/pisa/pisa2012/presentacion2012>. Acceso en: 10 mayo 2014.

CARDOZO, Santiago. Políticas de Educación. Montevideo: Mides-Infamilia, 2008.

CASAL, Joaquim. Modos Emergentes de Transición a la Vida Adulta en el Umbral del Siglo XXI: aproximación sucesiva, precariedad y desestructuración. Reis, Madrid, v. 75, p. 295-316, 1996.

DE ARMAS, Gustavo; RETAMOSO, Alejandro. La Universalización de la Educación Media en Uruguay: tendencias asignaturas pendientes y retos a futuro. Montevideo: UNICEF, 2010.

FILARDO, Verónica. Calendarios y Perspectivas Temporales de los Jóvenes de Uruguay. In: Congreso de la Asociación Latinoamericana de Sociología, 18, 2013, Santiago de Chile. Anais... Santiago de Chile: 2013.

FILARDO, Verónica. Transiciones a la Adultez y Educación. Montevideo: UNFPA, 2010.

FILARDO, Verónica; PLANEL, Anaclara; NAPILOTI, Romina. Sobre la Brecha de Fecundidad en Uruguay. Montevideo: Comisión Sectorial de Población, 2011.

FILARDO, Verónica. Brechas de Fecundidad: desear, proyectar y tener hij@s. El Uruguay desde la Sociología, Montevideo, v. 10, p. 141-162, 2012.

FILARDO, Verónica. Distancias Intra-Generacionales: jóvenes en Uruguay 1990-2008. Montevideo: Inju Mides, 2011.

FILARDO, Verónica; BORRÁS, Veronica. El Acceso al Sistema Educativo de los Jóvenes: análisis de tres países latinoamericanos en base a las encuestas de juventud. In: JORNADAS DE INVESTIGACIÓN DE LA FACULTAD DE CIENCIAS SOCIALES, 14, 2015, Montevideo. Anais... Montevideo: 2015.

LECCARDI, Carmen; RAMPAZI, Marita. Past and Future in Young Women's Experience of Time. Time \& Society, v. 2, n. 3, p. 353-379, 1993.

LECCARDI, Carmen. Tiempo y Construcción Biográfica en la Sociedad de la Incertidumbre: reflexiones sobre las mujeres jóvenes. Nómadas, Bogotá, v. 16, p. 43-50, 2002.

PERI, Andrés. Primero una Sola Vez: repitiendo argumentos contra la repetición. Montevideo: ANEP, 2008.

Verónica Filardo es doctora en Sociología. Profesora Titular de la UdelaR. Coordinadora del Grupo de Estudios Urbano Generacionales. Investigadora del SNI- ANII.

E-mail: filardo.veronica@gmail.com

40 Educação \& Realidade, Porto Alegre, v. 41, n. 1, p. 15-40, ene./mar. 2016 